nonalcoholic fatty liver disease). Actual problems of modern medicine: Bulletin of the Ukrainian Medical Dental Academy, 12/3 (39), 46-50.

10. Paschos, P., Tziomalos, K. (2012). Nonalcoholic fatty liver disease and the reninangiotensin system: Implications for treatment . World J. Hepatol., 4 (12), 327-331.

11. Yoshiji, H., Kuriyama, S., Fukui, H. (2007). Blockade of renin-angiotensin system in antifibrotic therapy. Journal of Gastroenterology and Hepatology, 22 (s1), 893-895. doi: 10.1111/j.1440-1746.2006.04663.x

12. Huang, M. L., Li, X., Meng, Y., Xiao, B., Ma, Q., Ying, S. S., Wu, P. S., Zhang, Z. S. (2010). Upregulation of angiotensin-converting enzyme (ACE) 2 in hepatic fibrosis by ACE inhibitors. Clinical and Experimental Pharmacology and Physiology, 37 (1). - P. 1-6. doi: 10.1111/j.1440-1681.2009.05302.x

13. Li, L., Luo, Z., Yu, H., Feng, X., Wang, P., Chen, J., Pu, Y., Zhao, Y., He, H., Zhong, J., Liu, D., Zhu, Z. (2013). Telmisartan improves insulin resistance of skeletal muscle through peroxisome proliferatoractivated receptor- $\delta$ activation. Diabetes, 62 (3), 762774. doi: $10.2337 / \mathrm{db} 12-0570$

14. Drake, J. I., Gomez-Arroyo, J., Dumur, C. I., Kraskauskas, D., Natarajan, R., Bogaard, H. J., Faw- cett, P., Voelkel, N. F. (2013). Chronic carvedilol treatment partially reverses the right ventricular failure transcriptional profile in experimental pulmonary hypertension. Physiological Genomics, 45 (12), 449-461. doi: 10.1152/physiolgenomics.00166.2012

15. Hobolth, L., Bendtsen, F., Hansen, E. F. (2014). Effects of carvedilol and propranolol on circulatory regulation and oxygenation in cirrhosis: a randomised study. Digestive and Liver Disease, 46 (3), 251-256. doi: 10.1016/j.dld.2013.10.013

16. Ko, S. Y., Kim, J. H., Choe, W. H., Kwon, S. Y., Lee, C. H. (2012). Pharmacotherapy alone vs endoscopic variceal ligation combination for secondary prevention of oesophageal variceal bleeding: meta-analysis. Liver International, 32 (5), 867-869. doi: 10.1111/j.14783231.2011.02681.x

17. Vize-Hripunova, M. A., Zagoranskaya, N. S., Ismailova, S. A. (2005). Effektivnost lizinoprila v korrektsii portalnoy gipertenzii u bolnyih tsirrozom pecheni (Efficacy of lisinopril in the correction of portal hypertension in patients with liver cirrhosis). Russian Journal of Gastroenterology, Hepatology and Coloproctology, 26, 69 .

Рекомендовано до публікації д-р мед. наук Крахмалова О. О. Дата надходження рукопису 14.11.2014

Козлов Александр Петрович, ассистент, кафедра гигиены и социальной медицины медицинского факультета, Харьковский национальный университет им. В. Н. Каразина, пл. Свободы, 6, г. Харьков, Украина, 61077

E-mail:kozlov@karazin.ua

УДК 612.111: 612.135

DOI: $10.15587 / 2313-8416.2014 .35085$

\title{
К ОБЪЯСНЕНИЮ МЕХАНИЗМА ВЛИЯНИЯ СДВИГОВОГО НАПРЯЖЕНИЯ НА ВЯЗКОСТНЫЕ ПАРАМЕТРЫ КРОВИ В СОСУДАХ МАЛОГО ДИАМЕТРА
}

\section{(С) Л. Н. Катюхин}

В работе приводятся данные экспериментального подтверждения и физиологическое объяснение феномена Фареуса-Линдквиста в капиллярах, используя анализ профилей осмотической деформируемости красных клеток крови. Показано дозозависимое изменение деформируемости эритроцитов в стадии изотропной сферы при формировании искусственных водных пор (нистатин) и закупорке $\left(\mathrm{PbCl}_{2}\right)$ имеющихся. Сигма-эффект снижения гематокрита и вязкости в сдвиговом потоке крови через сосуды малого диаметра вызывается обменом жидких фаз между эритрочитом и плазмой Ключевые слова: сигма-эффект, вязкость, эритрочиты, деформируемость, водные поры, напряжение сдвига

It is proposed a physiological and experimentally confirmed explanation of Fåhraeus-Lindqvist-effect in capillaries using the profile analyses of osmotic deformability of red blood cells. It was shown the dosedependent change of the erythrocytes deformability in the stage of isotropic spheres after forming artificial water pores (nystatin) and occlusion $\left(\mathrm{PbCl}_{2}\right)$ of available pores. The Sigma-effect reducing of hematocrit and viscosity in a shear flow of blood through the vessels of a small diameter was conditioned by the interchange of liquid phase between the erythrocyte and the plasma

Keywords: sigma-effect, viscosity, erythrocytes, deformability, water pores, shear stress 


\section{1. Введение}

Согласно закону Пуазейля с уменьшением диаметра трубки вязкость текущей однородной ньютоновской жидкости повышается. Однако кровь, как неоднородная неньютоновская жидкость, ведет себя иначе. Впервые описанный в 1931 году сигмафеномен, который проявляется сосудах диаметром менее 300 мкм в виде снижения гематокрита (R. Fahreus-effect) и вязкости крови (R. FahreusT. Lindqvist-effect) [1], вызвал поток теоретических исследований, продолжающийся до сих пор [2-5].

\section{2. Анализ литературных данных и постановка проблемы \\ Эффект Фареуса-Линдквиста облегчает} движение крови в капиллярах кровеносного русла: формируя цилиндрическую осевую трубку тока, эритроциты скользят по слою окружающей их плазмы. Считается, что эффект достигается за счет того, что эритроцитов в движущейся по узким сосудам крови становится меньше, т. к. часть из них задерживается при вхождении крови в узкие сосуды и вследствие смещения эритроцитов в сдвиговом потоке. Это приводит к возникновению бедной клетками маргинальной зоны, которая ускоряет движение жидкого ядра [6-8]. Авторы в своих сугубо математических выкладках рассматривают только феноменологию события, основываясь на факте миграции эритроцитов в малых сосудах в направлении осевой зоны с образованием пристеночного слоя плазмы. Существует все же некоторая неопределенность в вопросе относительно роли упомянутых факторов и их биологической значимости в механизмах эффекта, реальная причина которого остается загадочной. Описанию физиологического механизма уменьшения гематокрита и вязкости крови в связи с увеличением напряжения сдвига и связанного с этим процессом деформационных изменений эритроцитов и посвящена данная работа.

3. Материал и методы исследований деформируемости эритроцитов в форме изотропной сферы

На сегодняшний день важнейшими детерминантами деформационных свойств эритроцитов являются вязкость внутреннего содержимого, или степень гидратированности гемоглобина, соотношение площади поверхности и объема, или $\mathrm{S} / \mathrm{V}$, и степень ригидности мембраны. На наш взгляд степень деформирумости зависит и от присутствия липидных пор в мембране, через которые возможен обмен жидкими фазами внутренних и наружных областей клеток в условиях изменения напряжения сдвигового потока крови.

В работе использована кровь 10 лабораторных крыс линии Вистар. Исследования проводились на установке собственного изготовления по методике градиентной эктацитометрии [9]. В зазоре ячейки Куэтта с суспензионной средой вязкостью 10 сР при скорости вращения 100 об/мин развивается скорость сдвига $1050 \mathrm{C}^{-1}$ и напряжение сдвига 10,5 H/M², что близко к условиям течения в кровяных капиллярах $[10,11]$. Профиль осмотической деформируемости, или осмоскан, характеризует изменения эктацитометрического индекса деформируемости (Іэ) от осмоляльности суспензионной среды. Для количественной оценки Іэ используется эктацитометрический показатель (А-Б)/(А+Б), где А и Б - интенсивности освещения по большой и малой осям дифракционного образа эритроцитов в потоке. На графике выделяют несколько характеристических точек: Омакс - осмоляльность, при которой наблюдается наивысший Iэ, соответствует изотоничному значению в крови; Омин осмоляльность, при которой отмечается минимальная величина Іэ, является точной мерой отношения S/V эритроцита, Імин - значение деформируемости в точке изотропного набухания эритроцита.

Плазму отделяли от эритроцитов аспирацией после центрифугирования гепаринизированной (100 ед/мл) крови при 600g. Далее производилась однократная отмывка эритроцитов в HEPESзабуференном растворе физиологической ионной силы следующего состава (в мМ): $145 . \mathrm{NaCl}, 7,5 \mathrm{KCl}$, 10 глюкоза и 10 HEPES при $\mathrm{pH} 7,4$ и комнатной температуре. Для блокировки водных каналов использовали $\mathrm{HgCl}_{2}$ (SIGMA-ALDRICH) в концентрациях $2 \cdot\left(10^{-5}-10^{-3}\right) \mathrm{M}$, которые готовили на фосфатном буфере. Эритроциты и буфер, содержащий разные концентрации $\mathrm{HgCl}_{2}$, смешивались в равных пропорциях [12]. Длительность инкубации составляла 1 час при $25^{\circ} \mathrm{C}$. Водные каналы в липидном бислое эритроцитов формировали полиеновым антибиотиком нистатином, который, взаимодействуя с мембранными стеролами, повышает водную, электролитную и неэлектролитную проницаемость холестеринсодержащего липидного бислоя и вызывает формирование пор с радиусом 0.36-0.37 $\mathrm{nm}$. Нистатин (SIGMA-ALDRICH) растворяли в диметилсульфоксиде. Инкубацию отмытых эритроцитов с нистатином в концентрациях $\left(2 \cdot 10^{-6}-10^{-5}\right) \mathrm{M}$ проводили в течение 30 мин при $25^{\circ} \mathrm{C}$. Конечная концентрация растворителя в исследуемой среде составляла менее $0,01 \%$ [13]. Эксперименты проводились с суспензией эритроцитов после удаления супернатанта. Данные представлены в виде средних арифметических значений с их среднеквадратическими ошибками. Сравнение индексов деформируемости эритроцитов суспензий обработанных нистатином и сулемой выполнены с помощью парного t-теста. Отличия между величинами $<0,05$ считались достоверными.

3. Результаты исследований изменения деформируемости эритроцитов при модефицировании водной проницаемости мембраны

На рис. 1, 2 представлены графики экспериментов с нистатином и $\mathrm{HgCl}_{2}$. 


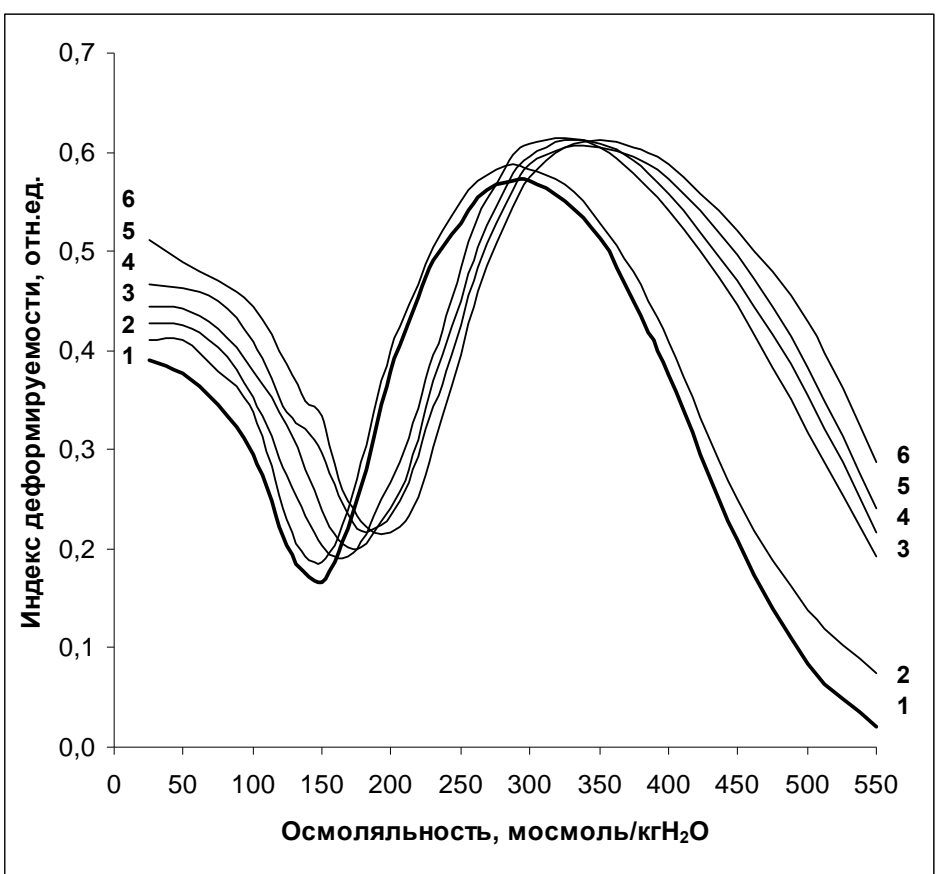

Рис. 1. Профили осмотической деформируемости эритроцитов до и после инкубации с нистатином. Кривые 2-6 представляют образцы с прогрессивным нарастанием концентрации нистатина: 1 - контроль; 2 - 1 мкМ;

$$
3 \text { - } 2 \text { мкМ; } 4 \text { - } 5 \text { мкM; 5 - } 10 \text { мкM; 6 - } 20 \text { мкМ }
$$

На осмосканах (рис. 1) отмечается отчетливое дозозависимое повышение значений показателя Імин и Іэ в изотонической зоне от количества сформированных пор в мембранах эритроцитов, тогда как рис. 2 показывает дозозависимое снижение способности эритроцитов деформироваться как в точке изотропного набухания, так и в изотонической зоне в зависимости от числа блокированных пор. В табл. 1 представлены численные значения индекса деформируемости Імин в результате примененных воздействий. Отмечено достоверное повышение показателя в случае увеличения числа гидрофильных пор в мембране эритроцита и снижение при их блокаде

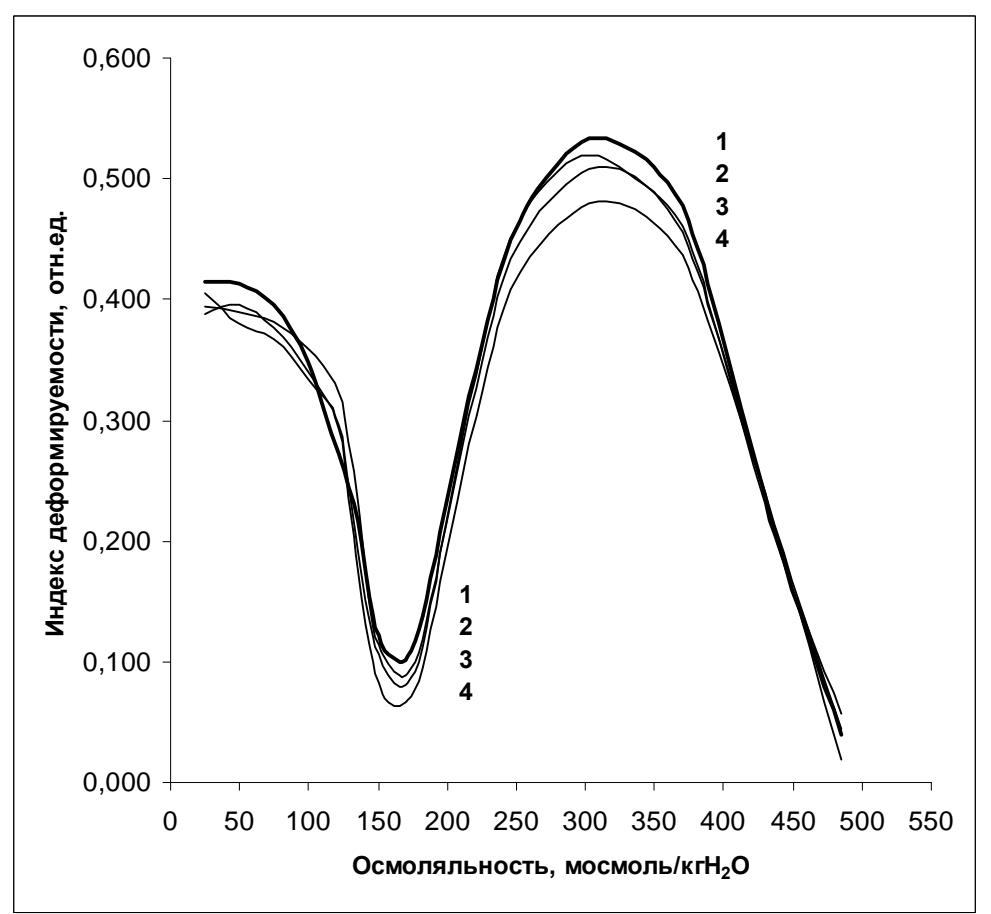

Рис. 2. Профили осмотической деформируемости эритроцитов до и после инкубации с $\mathrm{HgCl}_{2}$. Кривые $2-4$ представляют образцы с прогрессивным нарастанием концентрации $\mathrm{HgCl}_{2}: 1$ - контроль; 2 - 20 мкM;

$$
3 \text { - } 50 \text { мкМ; } 4-100 \text { мкМ }
$$


Таблица 1

Значения Імин в экспериментах с нистатином и $\mathrm{HgCl}_{2}$

\begin{tabular}{|c|c|c|c|}
\hline \multicolumn{2}{|c|}{ Нистатин } & \multicolumn{2}{|c|}{$\mathrm{HgCl}_{2}$} \\
\hline Контроль, $\mathrm{n}=5$ & $0,167 \pm 0,008$ & Контроль, $\mathrm{n}=5$ & $0,102 \pm 0,007$ \\
\hline 1 мкM, n=5 & $0,187 \pm 0,008$ & 20 мкM, n=5 & $0,088 \pm 0,005$ \\
\hline 2 мкM, n=5 & $0,190 \pm 0,008$ & 50 мкM, n=5 & $0,081 \pm 0,005^{*}$ \\
\hline 5 мкM, n=5 & $0,200 \pm 0,008^{*}$ & 100 мкM, n=5 & $0,063 \pm 0,004 * * *$ \\
\hline 10 мкM, n=5 & $0,212 \pm 0,009 * * *$ & & \\
\hline 20 мкM, n=5 & $0,219 \pm 0,010 * *$ & & \\
\hline
\end{tabular}

В табл. 2 представлены численные значения Іэ в изотонической области.

Таблица 2

Значения Іэ в экспериментах с нистатином и $\mathrm{HgCl}_{2}$

\begin{tabular}{|c|c|c|c|}
\hline \multicolumn{2}{|c|}{ Нистатин } & \multicolumn{2}{c|}{$\mathrm{HgCl}_{2}$} \\
\hline Контроль, $\mathrm{n}=5$ & $0,575 \pm 0,007$ & Контроль, $\mathrm{n}=5$ & $0,528 \pm 0,010$ \\
\hline 1 мкM, $\mathrm{n}=5$ & $0,588 \pm 0,008^{*}$ & 20 мкM, $\mathrm{n}=5$ & $0,517 \pm 0,008^{*}$ \\
\hline 2 мкM, $\mathrm{n}=5$ & $0,617 \pm 0,009^{* * *}$ & 50 мкM, $\mathrm{n}=5$ & $0,502 \pm 0,008^{* *}$ \\
\hline 5 мкM, $\mathrm{n}=5$ & $0,613 \pm 0,012^{* * * *}$ & $100 \mathrm{мкM}, \mathrm{n}=5$ & $0,475 \pm 0,006^{* * *}$ \\
\hline 10 мкM, $\mathrm{n}=5$ & $0,612 \pm 0,008^{* * *}$ & & \\
\cline { 1 - 2 } 20 мкM, $\mathrm{n}=5$ & $0,608 \pm 0,010^{* *}$ & &
\end{tabular}

Максимальная деформирумость достоверно возрастает при увеличения числа гидрофильных пор и снижается при их блокаде. Приведенные концентрации реактивов не разрушают мембраны и наглядно демонстрируют картину качественных изменений деформационных свойств эритроцитов в модельных экспериментах.

\section{4. Обсуждение результатов влияния} модификации водной проницаемости на деформационные свойства эритроцитов в зоне инверсии

Биологические мембраны образуют протяженные рыхлоупакованые бислойные структуры с относительно малыми микровязкостью и толщиной (6-10 нм), объединяющие белковые и липидные компоненты с различными свойствами. Непрерывность его определяет барьерные и механические свойства клетки. Мембранные липиды, обладающие мезоморфизмом, могут находиться в двух основных ламеллярных состояниях, кристаллическом и жидкокристаллическом, которые различаются плотностью упаковки и подвижностью находящихся в бислое белковых молекул. Фазовые переходы приводят к повышению подвижности ацильных цепей в бислое, увеличению угла их наклона и уменьшению плотности упаковки, латеральная подвижность мембранных белков возрастает, увеличивается вероятность образования их ассоциатов.

В процессе жизнедеятельности нативная структура бислоя может нарушаться с образованием структурных дефектов. Проницаемость мембраны для воды очень высока. Предполагают, что она может проходить через временные структурные дефекты, формирующиеся при тепловых колебаниях хвостов жирных кислот. Эти дефекты (кинки) позволяют перемещаться через мембрану не только молекулам воды, но также другим небольшим гидрофильным молекулам (кислород, углекислый газ).

При помещении эритроцитов в гипоосмотические условия вода по концентрационному градиенту устремляется внутрь клетки, ее объем увеличивается. В предгемолитической стадии эритроцит приобретает форму изотропной сферы. Принципиально в этой точке деформационые свойства мембраны не играют существенного значения, эритроцит недеформируем. Однако в ячейке Куэтта он испытывает сдвиговое напряжение, стремящееся изменить его форму. При сохранении объема изменение формы может произойти только в результате увеличении площади, поскольку сфера имеет максимальный объем для данной поверхности. Но модуль удлинения (дилатации), определяемый свойствами липидного бислоя как двумерной несжимаемой жидкости, столь велик, что при всех неразрушающих деформациях площадь поверхности эритроцита остается неизменной, и мембрана в физиологических условиях нерастяжима [14]. Сдвиговое усилие вызывает подъем гидростатического давления, что приводит к уменьшению объема по сравнению с максимальным критическим вследствие выхода жидкой фазы в суспензионную среду через гидрофильные поры. По нашим представлениям в точке Омин клетки обладают способностью изменять сферическую форму вследствие обмена жидкими фазами между содержимым эритроцита и суспензионной средой в сдвиговом потоке. Степень этих деформационных изменений зависит от числа мест выхода жидкой фазы из эритроцита. Разработчики метода [15] при исследовании клеточных популяций, изолированных в градиенте плотности, показали, что не все клетки достигают критического объема при одной осмоляльности. На этом основании остаточную деформируемость Імин при Омин они объясняют полиморфизмом 
эритроцитов. Однако авторы не рассматривали возможности обмена жидкими фазами при деформации клеток. На наш взгляд полиморфизм эритроцитов изменяет лишь ширину зоны инверсии и в меньшей степени остаточную деформируемость. Между тем, эктацитометрия при анемических состояниях, в частности при серповидноклеточной анемии, показывает извращенное поведение осмосканов, в особенности в точке Омин [16-19]. Наши многолетние исследования свидетельствуют о том, что в нативном состоянии деформируемость в точке инверсии оказывается неизменно ниже, чем при разнообразных воздействиях, будь то патология или стресс.

Как видно из представленных рисунков, минимальная деформируемость в точке инверсии повышается с повышением концентрация антибиотика в суспензионной среде и снижается, когда использовали блокирующий агент. Однако общая картина осмосканов также претерпевает изменения. Так, при формировании дополнительных пор в мембранах (рис. 1) нативная осморегуляция нарушается, и происходит изменение формы эритроцитов, и возрастание гидратации гемоглобина вследствие поступления воды внутрь клетки. Точка Омин сдвигается в гиперосмотическую зону, что свидетельствует о набухании эритроцитов. Что же касается точки Омакс, то это следствие сдвига характеристической точки О', которая характеризует правое крыло осмоскана, отмечается согласно исследованиям разработчиков метода при осмоляльности, соответствующей $1 / 2$ Омакс и отражает степень гидратации гемоглобина. Более гидратированный гемоглобин отдает воду в более гиперосмотических условиях суспензионной среды. Поэтому правое крыло и сдвигается вправо вместе с точкой Омакс. Когда же поры блокируются (рис. 2), то происходит «консервация» внутренней водной фазы, и изменения профиля осмоскана не происходит. Однако мембрана «нагружается» солью тяжелого металла и становится ригиднее, о чем и свидетельствует снижение Омакс. Данные произведенных экспериментов представлены в узком диапазоне концентраций нистатина и сулемы, начиная с минимально заметного эффекта. Приведенные концентрации реактивов не разрушают мембраны и наглядно демонстрируют картину качественных изменений деформационных свойств эритроцитов в модельных экспериментах. Увеличение концентраций, судя по качественному изменению картины осмосканов, вызывает резкое нарушение осморегулирующих систем, расстройство работы ионных каналов и выраженный гемолиз эритроцитов.

Коллоидная система стабилизирует вязкостный гомеостазис крови до критических участков кровотока, где диаметр сосудов становится меньше 150 мкм. Физиологическое значение феномена состоит в обеспечении протекания крови в венозных капиллярах и при патологии, когда форма переносчиков кислорода изменена. В макромире похожая ситуация складывается, к примеру, при замешивании сыпучих цементсодержащих смесей, когда небольшой избыток воды приводит к скачкообразному снижению вязкости суспензии.

\section{5. Выводы}

В сосудах малого диаметра возрастающее напряжение сдвига вынужденно изменяет форму переносчиков кислорода. Это вызывает перемещение жидкой фазы по градиенту давления из эритроцита в просвет капилляра, следствием чего и является и снижение гематокрита, и вязкости крови. Таким образом, механизм «загадочного» эффекта ФареусаЛиндквиста - в «лишней» воде. Надеемся, что дальнейшие исследования с применением меченых сред и флуоресцентных красителей, а также эксперименты с приготовлением буферных растворов на тяжелой воде и последующем стрессе при пропускании эритроцитарной суспензии через миллипоровые фильтры либо посредством шпринцевания, подтвердят наше заключение.

\section{Литература}

1. Fåhraeus, R. The viscosity of the blood in narrow capillary tubes [Text] / R. Fåhraeus, T. Lindqvist // Am. J. Physiol. - 1931. - Vol. 96. - P. 562-568.

2. Медведев, А. Е. Двухфазная модель течения крови [Текст] / А. Е. Медведев // Российский журнал биомеханики. - 2013. - Т. 17, № 4(62). - С. 22-36.

3. Moyers-Gonzalez, M. A non-homogeneous constitutive model for human blood. Part. 1. Model derivation and steady flow [Text] / M. Moyers-Gonzalez, R. G. Owens, J. Fang // Journal of Fluid Mechanics. - 2008. - Vol. 617. P. 327-453. doi: 10.1017/s002211200800428x

4. Pries, A. R. Blood Flow in Microvascular Networks [Text] / A. R. Pries, T. W. Secomb; R. F. Tuma, W. N. Dura, K. Ley (Eds.). - Handbook of Physiology: Microcirculation. Academic Press, 2008. - P. 3-36. doi: 10.1016/b978-0-12374530-9.00001-2

5. Sharan, M. A two-phase model for flow of blood in narrow tubes with increased effective viscosity near the wall [Text] / M. Sharan, A. S. Popel // Biorheology. - 2001. Vol. 38. - P. 415-428.

6. Пономаренко, Г. Н. Биофизические основы физиотерапии [Текст] / Г. Н. Пономаренко, И. И. Турковский. - М.: Медицина, 2006. - 176 с.

7. Huo, Y. Effect of compliance and hematocrit on wall shear stress in a model of the entire coronary arterial tree [Text] / Y. Huo, G. S. Kassab // Journal of Applied Physiology. 2009. - Vol. 107, Issue 2. - P. 500-505. doi: 10.1152/japplphysiol.91013.2008

8. Xue, X. Modelling and simulation of the behaviour of a biofluid in a microchannel biochip separator [Text] / X. Xue, M.K. Patel, M. Kersaudy-Kerhoas, C. Bailey, M. P. Desmulliez $/ /$ Computer Methods in Biomechanics and Biomedical Engineering. - 2011. - Vol. 14, Issue 6. - P. 549-560. doi: 10.1080/10255842.2010.485570

9. Johnson, R. M. Ektacytometry of red blood cells [Text] / R. M. Johnson // Methods in Enzymology. - 1989. Vol. 173 (T). - P. 35-54. doi: 10.1016/s0076-6879(89)73004-4

10. Charm, S. E. Blood Rheology [Text] / S. E. Charm, G. S. Kurland. - In: Cardiovascular fluid dynamics. Vol. 2. Acad. press, London \& New York, 1972. - 202 p.

11. Schmid-Schönbein, H. Factors promoting and preventing the fluidity of blood [Текст] / H. SchmidSchönbein. - In: Microcirculation. Current physiologic, medical, and surgical concepts. Acad press, N. Y., London, Toronto, Sydney, San-Francisco, 1981. - 250 p. 
12. Tsai, S. T. High channel-mediated water permeability in rabbit erythrocytes: characterization in native cells and expression in Xenopus oocytes [Text] / S. T. Tsai, R. B. Zhang, A. S. Verkman // Biochemistry. - 1991. Vol. 30. - P. 2087-2092. doi: 10.1021/bi00222a013

13. Katsu, T. Precise size determination of amphotericin $\mathrm{B}$ and nystatin channels formed in erythrocyte and liposomal membranes based on osmotic protection experiments [Text] / T. Katsu, S. Okada, T. Imamura, K. Komagoe, K. Masuda, T. Inoue, S. Nakao // Analytical Sciences. - 2008. - Vol. 24, Issue 12. - P. 1551-1556. doi: 10.2116/analsci.24.1551

14. Ивенс, И. Механика и термодинамика биологических мембран [Текст] / И. Ивенс, Р. Скейлак. М.: Мир, 1982. -304 с.

15. Clarc, M. R. Osmotic gradient ektacytometry: comprehensive characterization of red cell volume and surface maintenance [Text] / M. R. Clarc, N. Mohandas, S. B. Shohet // Blood. - 1983. - Vol. 61, Issue 5. - P. 899-910.

16. Bossi, D. Hemolytic anemias due to disorders of red cell membrane skeleton [Текст] / D. Bossi, M. Russo // Molecular Aspects of Medicine. - 1996. - Vol. 17, Issue 2. P. 171-188. doi: 10.1016/0098-2997(96)88346-4

17. Johnson, R. M. Osmotic scan ektacytometry in clinical diagnosis [Text] / R. M. Johnson, Y. Ravindranath // Journal of Pediatric Hematology/Oncology. - 1996. - Vol. 18, Issue 2. - P. 122-129. doi: 10.1097/00043426-19960500000005

18. Streekstra, G. J. Quantification of the fraction poorly deformable red blood cells using ektacytometry [Text] / G. J. Streekstra, J. G. Dobbe, A. G. Hoekstra // Optics Express. - 2010. - Vol. 18, Issue 13. - P. 14173-14182. doi: 10.1364/oe.18.014173

19. Tillmann, W. Reduced deformability of erythrocytes as a common denominator of hemolytic anemias [Text] / W. Tillmann // Wien. Med. Wochenschr. - 1986. - Vol. 136. P. 14-16.

\section{References}

1. Fåhraeus, R., Lindqvist, T. (1931). The viscosity of the blood in narrow capillary tubes. Am. J. Physiol., 96, 562568 .

2. Medvedev, A. E. (2013). Dvuhfaznaja model' techenija krovi. Rossijskij zhurnal biomehaniki, 17, 4 (62), 22-36.

3. Moyers-Gonzalez, M., Owens, R. G., Fang, J. (2008). A non-homogeneous constitutive model for human blood. Part. 1. Model derivation and steady flow. Journal of Fluid Mechanics, 617, 327-453. doi: 10.1017/s002211200800428x

4. Pries, A. R., Secomb, T. W.; Tuma, R. F., Dura, W. N., Ley, K. (Eds.) (2008). Blood Flow in Microvascular Networks. In: Handbook of Physiology: Microcirculation. Academic Press, 3-36. doi: 10.1016/b978-0-12-374530-9.00001-2

5. Sharan, M., Popel, A. S. (2001). A two-phase model for flow of blood in narrow tubes with increased effective viscosity near the wall. Biorheology, 38, 415-428.
6. Ponomarenko, G. N., Turkovskij, I. I. (2006). Biofizicheskie osnovy fizioterapii. Moscow: Medicine, 176.

7. Huo, Y., Kassab, G. S. (2009). Effect of compliance and hematocrit on wall shear stress in a model of the entire coronary arterial tree. Journal of Applied Physiology, 107 (2), 500-505. doi: 10.1152/japplphysiol.91013.2008

8. Xue, X., Patel, M. K., Kersaudy-Kerhoas, M., Bailey, C., Desmulliez, M. P. (2011). Modelling and simulation of the behaviour of a biofluid in a microchannel biochip separator. Computer Methods in Biomechanics and Biomedical $\begin{array}{llll}\text { Engineering, } & 14 & (6), & 549-560 .\end{array}$ $10.1080 / 10255842.2010 .485570$

9. Johnson, R. M. (1989). Ektacytometry of red blood cells. Methods in Enzymology, 173 (T), 35-54. doi: 10.1016/s0076-6879(89)73004-4

10. Charm, S. E., Kurland, G. S. (1972). Blood Rheology. In: Cardiovascular fluid dynamics. Vol. 2. Acad. press, London \& New York, 202.

11. Schmid-Schönbein, H. (1981). Factors promoting and preventing the fluidity of blood. Microcirculation. Current physiologic, medical, and surgical concepts. Acad press: N. Y., London, Toronto, Sydney, San-Francisco, 317.

12. Tsai, S. T., Zhang, R. B., Verkman, A. S. (1991). High channel-mediated water permeability in rabbit erythrocytes: characterization in native cells and expression in Xenopus oocytes. Biochemistry, 30, 2087-2092. doi: $10.1021 / \mathrm{bi00222a013}$

13. Katsu, T., Okada, S., Imamura, T., Komagoe, K., Masuda, K., Inoue, T., Nakao, S. (2008). Precise size determination of amphotericin B and nystatin channels formed in erythrocyte and liposomal membranes based on osmotic protection experiments. Analytical Sciences, 24 (12), 1551-1556. doi: 10.2116/analsci.24.1551

14. Ivens, I., Skejlak, R. (1982). Mehanika i termodinamika biologicheskih membran. Moscow: Mir, 304.

15. Clarc, M. R., Mohandas, N., Shohet, S. B. (1983). Osmotic gradient ektacytometry: comprehensive characterization of red cell volume and surface maintenance. Blood, 61 (5), 899-910.

16. Bossi, D., Russo, M. (1996). Hemolytic anemias due to disorders of red cell membrane skeleton. Molecular Aspects of Medicine, 17 (2), 171-188. doi: 10.1016/00982997(96)88346-4

17. Johnson, R. M., Ravindranath, Y. (1996). Osmotic scan ektacytometry in clinical diagnosis. Journal of Pediatric Hematology/Oncology, 18 (2), 122-129.

doi: 10.1097/00043426-199605000-00005

18. Streekstra, G. J., Dobbe, J. G., Hoekstra, A. G. (2010). Quantification of the fraction poorly deformable red blood cells using ektacytometry. Optics Express, 18 (13), 14173-14182. doi: 10.1364/oe.18.014173

19. Tillmann, W. (1986). Reduced deformability of erythrocytes as a common denominator of hemolytic anemias. Wien. Med. Wochenschr., 136, 14-16.

Рекомендовано к публикации д-р мед. наук, проф. Шеповальников А. Н. Дата поступления рукописи 25.11.2014

Катюхин Лев Николаевич, кандидат физико-математических наук, доктор биологических наук, ведущий научный сотрудник лаборатории Сравнительной биохимии ферментов, Институт эволюционной физиологии и биохимии им. И. М. Сеченова, пр. Тореза, 44, ИЭФБ РАН, г. Санкт-Петербург, Россия, 194223

E-mail: Lion@iephb.ru 